\title{
Medical school admissions: where to next?
}

\author{
Vanessa C. Burch
}

Received: 6 March 2009/Accepted: 6 March 2009/Published online: 25 March 2009

(C) Springer Science+Business Media B.V. 2009

Identifying cognitive, non-cognitive and demographic variables that predict success at medical school is of major interest to university admissions committees worldwide given the cost of medical degree programmes and the social responsibility medical schools have to graduate competent physicians. Two papers in the current issue and one paper in the upcoming May issue, have evaluated a range of preadmission variables that predict performance in medical degree programmes (Kleshinski et al. 2009; Mills et al. 2009; White et al. 2009). What all three papers have in common is the observation that prior academic performance is the most important variable predicting subsequent academic success at university. This is in keeping with other published literature and the current studies, using novel methods of data analysis, provide further evidence in support thereof.

In the paper by White and colleagues (White et al. 2009) they used a technique called structural equation modelling to evaluate the interrelationships between selected preadmission variables such as undergraduate grade point average (UGPA) or Medical College Admissions Test (MCAT) scores and output variables such as performance in the United States Medical Licencing Examination (USMLE) or clinical performance as measured by overall clinical performance in a third year Internal Medicine clerkship. They demonstrate that UGPA predicted academic performance in the first year of study in all ethnic groups while MCAT scores did not predict early academic success in minority group students (African-American, Hispanics, Filipinos, Native Americans and Pacific Islanders). Earlier work has tended to show little influence of race on the predictive validity of MCAT scores (Koenig et al. 1998) or performance in the USMLE (Veloski et al. 2000). White also showed that MCAT scores predicted performance in the USMLE step 1, but not clinical performance as measured by multiple in-course evaluations (average of 11 per student) conducted by supervising clinicians during a 12-week clinical clerkship rotation. It is likely that this observation reflects the fact that both the MCAT and USMLE are tests measuring knowledge and the aptitude to acquire knowledge (Collins et al. 2008), whereas clerkship ratings possibly have more to do with professional attributes and clinical performance

\footnotetext{
V. C. Burch $(\bowtie)$

Department of Medicine, University of Cape Town, J Floor, Old Main Building,

Groote Schuur Hospital, Observatory, 7925 Cape Town, South Africa

e-mail: Vanessa.Burch@uct.ac.za
} 
in the workplace. Finally, overall performance in the second year at university was the best predictor of clinical performance in the third year clinical clerkship.

Kleshinski and colleagues (Kleshinksi et al. 2009) used linear regression analysis to identify predictors of success in the USMLE step 1 and 2 examinations and then developed neural networks in an attempt to more accurately predict step 1 and 2 scores from the preadmission data. They showed that significant predictors for success in the USMLE step 1 and step 2 included the science grade point average (SGPA), the biologic sciences section (BS) of the MCAT, college selectivity, race and age of the applicant. Their data show that younger students, white students and students from higher ranked (more selective) institutions performed best in the USMLE step 1 and 2 exams. Neural networks predicted a significant portion of the variance and demonstrated some superiority over that obtained by linear regression models.

In the paper by Mills and colleagues (Mills et al. 2009) they used regression analysis to demonstrate that success in the first year at a university in Australia was associated with a high matriculation score (Tertiary Entrance Examination), female sex, non-Indigenous status, attendance at a government secondary school, upfront payment of university fees and completion of secondary school English literature. Success in the second year of the programme was influenced by participation in the university mentor scheme, non-Indigenous status and first year university marks.

What are the implications of the findings described in these three papers? Firstly, traditional preadmission variables used to select candidates for medical school may not be applicable to all ethnic groups and other measures need to be found that do not discriminate against ethnic minority groups. White is explicit "Without MCAT as a reliable predictor for minority students, admissions committees are left with only the undergraduate GPA and more subjective - and potentially less valid and reliable — criteria for admissions decisions, including letters of recommendation and interviews." The ability of interviews to select candidates who are likely to succeed at medical school has been a source of considerable debate (Salvatori 2001). One novel approach to interviews that has demonstrated good reliability and an absence of ethnic bias is the multiple mini-interview used at McMaster University (Eva, Rosenfeld, et al. 2004a, b). This strategy subjects candidates to a series (9-10) of objective clinical examination (OSCE)-style stations in which applicants are presented with scenarios that require them to discuss a health-related issue (e.g. the use of placebos) with an interviewer, interact with a standardised confederate while an examiners observes the interpersonal skills displayed, or answer traditional interview questions This technique has been shown to have a reliability between 0.65 and 0.78 and the ethnicity of interviewers did not influence the scores achieved by candidates (Eva et al. 2004a, b). The ability of the multiple mini-interview to predict academic performance in medical school needs to be evaluated so as to strengthen the argument to be made for using this novel interview strategy as part of the medical school admissions selection process.

Both the papers by White and Kleshinski demonstrate the predictive relationship between UGPA and MCAT scores and performance in the USMLE. As suggested by White and colleagues this is "perhaps unremarkable given the similar nature of the assessments (i.e. both standardised tests)". What is of greater importance, however, is the observation by White and colleagues that both preadmission variables were poor predictors of clinical performance as assessed by clinicians supervising workplace-based clerkship rotations. This raises an important question "Are we measuring what we want to measure?" In 1998 it was already suggested by the Council on Graduate Medical Education that "standardized test performance might not predict success as a physician" (CGME 1998). Indeed, White and colleagues have shown that clinical performance was best 
predicted by academic performance in the earlier years of the programme rather than UGPA, MCAT or USMLE scores. It is therefore clear that if we want to graduate competent physicians we need to identify early predictors (preadmission if possible) of clinical competence prior to graduation. The use of in-course assessment of clinical performance appears to be an advance in terms of measuring a desirable output and should serve as the basis for future work exploring preadmission variables predictive of clinical competence as measured by in-course performance.

The three papers also raise issues regarding ethnic minority students and admission to medical school. As already discussed, White et al. demonstrated the limited predictive power of traditional preadmission variables in minority group students $(n=219,15 \%$ of cohort studied). In the other two papers the performance of ethnic minority students was evaluated. Kleshinski and colleagues showed that black students $(n=14,1.7 \%$ of cohort studied) performed less well in the USMLE step 1 and 2 and Mills et al. showed that first year Indigenous students ( $n=13,3.4 \%$ of cohort studied) in Australia performed less well than non-Indigenous students. The most striking feature of these papers is the small number of non-white students in the cohorts studied. This reflects the highly competitive nature of medical school admissions processes internationally and the limited ability of educationally disadvantaged students to compete with students from well-resourced backgrounds. Almost a decade ago Edelin and Ugbolue wrote "For more than 30 years there have been efforts to increase the number of medical students and physicians who come from racial and ethnic groups that are underrepresented in the medical profession" (Edelin and Ugbolue 2001). This begs the question "Why is progress so slow?" It is possible that not enough effort is being put into the process of making medical school more accessible to underrepresented minority students who have the potential to succeed. One such programme is the Early Medical School Selection Programme conducted by the Boston University School of Medicine (Edelin and Ugbolue 2001). They have a successful track record of 25 years of recruiting second year college students of mainly black and Mexican-American origin into a programme blending their bachelor's degree programme with courses from the first year medical programme in order to prepare them for medical school. The most remarkable feature of this programme is that $82 \%$ of students had an MCAT admission score lower than the mean MCAT score of underrepresented minority students entering medical school by the traditional selection process. The authors make the point "This is not a lowering of standards, however, but rather an expansion of them in order to give underrepresented minority students the opportunity to successfully pursue careers in medicine."

Another example of a specially tailored programme promoting access to medical school training for students from educationally disadvantaged backgrounds comes from South Africa where revolutionary social and political reform is attempting to redress the inequities of previous policies of racial segregation ("apartheid" policies). Since 1980 the University of Cape Town has been admitting students from educationally disadvantaged communities to medical school with admission scores lower than those of students entering the programme through the traditional highly competitive route. Between 1980 and 1990 only a small minority of black students were permitted to enter medical school owing to national educational segregation policies. After 1990 black students had easier access to tertiary education but lacked the academic foundation needed to succeed. In response to this need, the university developed an Academic Development Programme (ADP) which provided academic assistance as well as flexibility allowing academically "at risk" students to complete the first 3 years of a 6 year programme over 3 years (Colborn 1995). Despite the success of this programme (more than 100 graduates), there was a stigma 
attached to the programme and students felt that academic segregation, largely on the basis of race, was still in operation. In response to this, and also the implementation of a problem-based learning (PBL) curriculum in 2002 it was decided to enter all students, including "at risk" students, to the new first year programme. On the basis of performance in the first 6 months of the programme struggling students are entered into an 18-month Intervention Programme (IP) in which they receive specially tailored academic support and additional training in the first and second semester courses. After successful completion of the IP students re-enter the mainstream programme. The early results of this programme show that approximately $50 \%$ of "at risk" students do not need to enter the IP and are able to successfully proceed through medical school at the expected rate (Alexander et al. 2005). Subsequent work has shown that "at risk" student retention in the new PBL programme is better than in the ADP and that their clinical performance in clinical clerkship rotations is also better (Burch et al. 2007). This highlights the potential academically disadvantaged students have that is not easily measured by their prior academic performance in poorly resourced schools or standardised entrance tests at university.

So, where to next? It is clear that traditional preadmission variables are not addressing all the needs of medical school admissions committees grappling with the problem of identifying students with potential who did not have the educational opportunities afforded more fortunate students. So, we need to identify variables that will predict success of all applicants not just those from privileged backgrounds. Having identified such students we need to provide additional support to ensure their subsequent success. Secondly we need to explore the predictive capacity of novel admissions strategies such as the multiple miniinterview strategy and determine its longer term utility. Thirdly, we need to identify robust markers of clinical competence so as to measure success in a more professionally authentic manner. These measures could then become the targets we aim for when selecting students for medical school.

\section{References}

Alexander, R., Badenhorst, E., \& Gibbs, T. (2005). Intervention programme: A supported learning programme for educationally disadvantaged students. Medical Teacher, 27, 66-70.

Burch, V. C., Sikakana, C. N. T., Yeld, N., Seggie, J. L., \& Schmidt, H. G. (2007). Performance of academically at-risk students in a problem-based learning programme: A preliminary report. Advances in Health Sciences Education: Theory and Practice, 12, 345-358.

Colborn, R. P. (1995). Affirmative action and academic support: African medical students at the University of Cape Town. Medical Education, 29, 110-118.

Collins, V. T., Violato, C., \& Hecker, K. (2008). Aptitude, achievement and competence in medicine: A latent variable path model. Advances in Health Sciences Education: Theory and Practice, doi: 10.1007/ s10459-008-9121-7.

Council on Graduate Medical Education. (1998). Twelfth report: Minorities in medicine. Available at http://www.cogme.gov/12.pdf. Accessed 17 March 2009

Edelin, K. C., \& Ugbolue, A. (2001). Evaluation of an early medical school selection programme for underrepresented minority students. Academic Medicine, 76, 1056-1059.

Eva, K. W., Rosenfeld, J., Reiter, H. I., \& Norman, G. R. (2004a). An admission OSCE: The multiple miniinterview. Medical Education, 38, 314-326.

Eva, K. W., Reiter, H. I., Rosenfeld, \& Norman, G. R. (2004b). The relationship between interviewers' characteristics and ratings assigned during a multiple mini-interview. Academic Medicine, 79, 602-609.

Kleshinski, J., Khuder, S. A., Shapiro, J. I., \& Gold, J. P. (2009). Impact of preadmission variables on USMLE step 1 and step 2 performance. Advances in Health Sciences Education: Theory and Practice, 14. doi: 10.1007/s10459-007-9087-x.

Koenig, J. A., Sireci, S. G., \& Wiley, A. (1998). Evaluating the predictive validity of MCAT scores across diverse applicant groups. Academic Medicine, 73, 1095-1106. 
Mills, C., Heyworth, J., Rosenwax, L., Carr, S., \& Rosenberg, M. (2009). Factors associated with the academic success of first year Health Sciences students. Advances in Health Sciences Education: Theory and Practice, 14. doi: 10.1007/s10459-008-9103-9.

Salvatori, P. (2001). Reliability and validity of admissions tool used to select students for the health professions. Advances in Health Sciences Education: Theory and Practice, 1, 159-175.

Veloski, J. J., Callahan, C. A., Xu, G., Hojat, M., \& Nash, D. B. (2000). Prediction of students' performance on licencing examinations using age, race, sex, undergraduate GPAs and MCAT scores. Academic Medicine, 75, S28-S30.

White, C. B., Dey, E. L., \& Fantone, J. C. (2009). Analysis of factors that predict clinical performance in medical school. Advances in Health Sciences Education: Theory and Practice, 14. doi: 10.1007/ s10459-007-9088-9. 